\title{
The economic logic of barnacle Balanus glanduia (Darwin) hiding behavior
}

\author{
L. M. Dill and J.F. Gillett \\ Deparment of Biological Sciences, Simon Fraser University, Burnaby, British Columbia, Canada
}

(Received 18 June 1990; revision received 2 July 1991; accepted 15 July 1991)

\begin{abstract}
A series of experiments was conducted on the intertidal barnacle Balanus glandula (Darwin) from the coast of British Columbia, Canada. The hiding times of individual barnacles in response to a simulated shadow (a sudden decrease in illumination) were recorded to test the hypothesis that these times reflect a trade-off between energy need and predation risk. Barnacles hid longer after having spent more time feeding before the shadow occurred. Smaller barnacles tended to have longer hiding times than did larger ones. Although no significant differences were observed between the hiding times of barnacles from different heights on the beach, hiding times decreased as the time of the next scheduled low tide approached. Hiding times also decreased as hunger level (starvation time) increased. The rate of cirral beat varied only with size (smaller barnacles had faster beat rates); height on the shore, tide level, and starvation time had no effect on beat frequency. Overall, these results support the idea that hiding behavior in barnacles is determined in an economic fashion, taking into account the costs as well as the benefits of the behavior.
\end{abstract}

Key words: Anti-predator behavior; Cost-benefit analysis; Decision making

\section{INTRODUCTION}

In situations where increased energy intake is accompanied by increased risk of predation, trade-offs must be made between the benefits of feeding and the associated risk of mortality, and this should be done in a way that enhances fitness (Dill, 1987). For example, an animal should weigh the cost of lost foraging opportunity (reduced growth and future reproduction) resulting from the performance of anti-predator behavior against the reduced risk of mortality. The decision of whether to flee approaching predators or to continue feeding is made in just such an economic fashion; the probability of fleeing depends on the benefit of continued feeding relative to the risk of predation, and can be altered by manipulating these benefits and costs experimentally (Ydenberg \& Dill, 1986). Lima \& Dill (1990) have recently reviewed a considerable body of evidence suggesting that animals can assess risk and use that information to guide their behavioral decisions.

Barnacles are sessile filter feeders. Both feeding and respiration involve the use of hydrostatically extended thoracic appendages, the cirri. In the presence of a predator,

Correspondence address: L.M. Dill, Department of Biological Sciences, Simon Fraser University, Burnaby, British Columbia V5A 1S6, Canada. 
a barnacle's only defense is to withdraw its cirri into its shell and wait for the danger to pass; the barnacle must decide (sensu Dill, 1987) how long to remain in hiding. Since barnacle growth and competitive success are correlated with food intake (Wethey, 1983), and the nunber of embryos per brood is, in turn, dependent upon the size of the individual (Hurley, 1973), lost feeding opportunity due to hiding can be costly to an individual barnacle's fitness. We examined the predator avoidance (hiding) response of the barnacle Balanzls glandula (Darwin) to test the general hypothesis that hiding time is influenced by the energetic needs of the barnacle since this determines the opportunity cost of hiding.

B. glandula, an unstalked (acorn) barnacle, is ubiquitous on the Pacific coast of North America, ranging from Southern California to the Aleutian Islands (Pilsbry, 1916). It is an intertidal barnacle and can respire in both air and water (Pearse et al., 1987). Like all members of the genus, $B$. glandula exhibits five kinds of cirral activity, of which three are associated with feeding: "pumping" and "normal beat" function in filter feeding, and "fast beat" functions in captorial feeding (Crisp \& Southward, 1961).

We conducted five separate experiments. Each experiment involved measuring the time a barnacle remained in its shell in response to a shadow; the experiments differed in the way in which the costs of the avoidance response were varied.

In the first experiment, the amount of time barnacles were allowed to feed before shadow stimulation was varied. As the amount of time spent feeding increases, each additional unit of feeding time becomes relatively less valuable (its marginal utility is reduced), and barnacles should be less willing to risk mortality. We therefore predicted that average hiding time would increase as the amount of time spent feeding increased.

In the second experiment, the hiding times (and cirral beat frequencies) of barnacles of four different sizes were measured. Since small barnacles have a higher metabolic requirement per unit weight (Wu \& Levings, 1978), we predicted that smaller barnacles would either exhibjt shorter hiding times or that they would compensate for their greater metabolic demands with faster cirral beat frequencies (as observed in several barnacle species; Crisp \& MacLean, 1990).

Hiding times of barnacles from three different heights on the shore were measured in a third experiment. We predicted that individuals found highest on the shore would have the shortest hiding times in response to a standard stimulus, since they spend less time underwater and should value each unit of feeding time more than individuals low on the shore. In other words, for barnacles found high in the intertidal, the cost of withdrawal should be relatively high and the point at which the costs of withdrawal outweigh the costs of predation risk should be reached sooner than for barnacles found lower in the intertidal. Palmer et al. (1982) also made this prediction, although they did not test it.

In the fourth experiment, we measured response times of barnacles in relation to the time remaining until the next scheduled low tide. As the time of low tide approaches, the relative lost opportunity cost of retraction should increase due to the decrease in the amount of feeding time that remains before the next tide-induced fast. We therefore predicted a progressive decrease in hiding time. 
In the last experiment, response times of barnacles at various stages of starvation were measured. We predicted that the value of feeding time would increase and, thus, that hiding times would decrease as length of time without food increased (Palmer et al., 1982). However, we anticipated that this would be true only up to a point, and that over a range of longer starvation times there would be no further change in hiding time.

Since individuals might compensate for high energetic needs or short feeding periods by feeding more rapidly, measurements of cirral beat frequency were conducted to supplement the findings of the above experiments. With the exception of Experiments II and $V$, these data were not obtained simultaneously with the hiding time data, but in separate experiments at a later date.

\section{METHODS}

B. glandula specimens were collected near loco, in Burrard Inlet, British Columbia, on flat stones roughly $7.5-14 \mathrm{~cm}$ diameter and possessing $\approx 30-50$ individuals (dead individuals were included in this count because their shells contribute to the effects of crowding). Immediately after collection, all other organisms found on the rocks were removed. Since freshly collected specimens show more regular cirral activity than those kept in the laboratory (Southward \& Crisp, 1965), specimens were used the day after their collection. Except where noted, collections took place in 1988, between May and September, the two spawning periods of B. glandula in British Columbia (Wu \& Levings, 1979); eggs were observed in samples of larger barnacles.

All barnacles were kept under the same conditions in the laboratory prior to testing. The seawater used in these experiments came from Burrard Inlet. Temperature varied from $9-14^{\circ} \mathrm{C}$, salinity ranged between $25-27 \%$, and $\mathrm{pH}$ remained constant at 7.7 . The lights in the laboratory followed the natural photoperiod. Barnacles were kept in filtered seawater overnight. Considering that $B$. improvisus and $B$. eburneus empty their guts in $10-11 \mathrm{~h}$ at $12-16^{\circ} \mathrm{C}$ (Svirenko, 1961), this should have allowed time for the barnacles to achieve a consistent, high hunger level. During the experiments, the barnacles were fed Artemia (brine shrimp) nauplii in such excess that removal by the barnacles essentially did not alter availability. Furthermore, the tendency of the brine shrimp to aggregate in the light increased their concentration near the individual barnacles examined.

The "shadow response" was measured as the time it takes an individual to resume fast beat after a shadow has been cast upon it (Palmer et al., 1982). The shadow remained cast while response time was measured. Resumption of fast beat was chosen as the indicator of the end of the hiding response because it is the cirral activity associated with captorial feeding (Southward \& Crisp, 1965), the sort of feeding used to capture prey the size of Artemia nauplii.

Shadows were simulated by shading a bright light (a 15-W microscope bulb) suspended $30 \mathrm{~cm}$ above the test tank. The cylindrical, plexiglass test tank was $14 \mathrm{~cm}$ 
in diameter and $11.5 \mathrm{~cm}$ deep (although it was never filled to capacity). Only one rock was present in the test tank at a time. The light had to pass through $2.5 \mathrm{~cm}$ of seawater since all experimental barnacles were immersed to that depth. The light was "focused" upon an individual barnacle by shining it through a perforation in a sheet of aluminum foil covering the test tank for a 10-min feeding period prior to shadow stimulation. The shadow was created by blocking the perforation with another piece of foil. Since the test tank walls were transparent, some light remained even while the shadow was cast. To prevent habituation, each barnacle was tested only once in all but the first experiment.

Measurements of cirral beat frequency were conducted by counting the number of full cirral sweeps of fast beating barnacles over a short time interval (10-30 s). These data were then used to calculate the number of beats occurring in $10 \mathrm{~s}$ (as per Southward, 1955).

Statistical tests were carried out using Statistix, a statistics package for the Apple computer. There were no serious deviations from normality, despite the occasional truncation of the distribution of hiding times at $60 \mathrm{~s}$ (see below). Where necessary, transformations were performed to equalize variances among groups; these are noted in the Results scetion, where appropriate.

\section{EXPERIMENT I: RESPONSE TIME VS. TIME SPENT FEEDING}

Response times were recorded at cach of nine preselected time intervals after feeding had been initiated. Individuals were assigned to three size classes by eye. Rostro-carinal opercular plate measurements werc subsequently obtained for 30 representatives of each nominal size group, yielding the mean sizes reported in Table $\mathrm{I}$.

This experiment was conducted from 7 to 20 July 1988. As the tide was rising to cover them, 60 individuals from each size category were collected on rocks at $+1 \mathrm{~m}$ (all heights are relative to Canadian chart datum). The day following collection these 180 barnacles each had their shadow responses measured three times at 15 -min intervals. (Pretrial tests did not indicate habituation when individuals were stimulated at 15-min intervals, although some habituation was apparent when individuals were stimulated at 10-min intervals.) For 20 individuals in each size category, hiding times were measured 5, 20 and $35 \mathrm{~min}$ after initiation of feeding; 60 others $(20 \times 3$ sizes) were tested at 10,25 and $40 \mathrm{~min}$, and 60 more at 15,30 and 45 min after feeding was initiated. The staggering of the tests yiclded response times for each 5-min interval between the time that feeding began and 45 min thereafter, without the need to disturb any individual barnacle that frequently.

Some individuals in this and subsequent experiments were not performing fast beat when it was time to measure their shadow response, and thus were not tested. As a result, sample sizes were often somewhat smaller than planned. 
EXPERIMENT II: RESPONSE TIME VS. BODY SIZE

On cach of 2 days (25 and 26 May 1989), barnacles were collected from the $1 \mathrm{~m}$ shore height as the tide was rising. In the laboratory, these barnacles were submerged in filtered seawater at the time they would have been submerged in nature. The following day, $3 \mathrm{~h}$ before the next scheduled tidal uncovering of these barnacles, they were allowed to feed for $10 \mathrm{~min}$ on Artemia before their cirral beat frequencies and shadow response times were measured. 20 individuals from each of four size groups were tested in this experiment. Size group $\mathrm{T}$ (mean rostro-carinal opercular plate length $=1.35 \pm 0.30 \mathrm{~mm}$ SD) was added to the three size classes used in Experiment $I$. The barnacles were starved for a total of $22-23 \mathrm{~h}$, including their time on the beach uncovered by the tide.

\section{EXPERIMENT III: RESPONSE TIME VS. HEIGHT ON SHORE}

During low tide on each of 3 collection days (23-25 August 1988), rocks were collected simultaneously at each of three different heights on the shore (nominally, 1 , 1.8 and $2.7 \mathrm{~m}$ ). Each of these nominal heights actually consisted of a set of five heights, beginning at the nominal height and progressing up the beach at tide height increments estimated to correspond to 15 -min time intervals. The actual shore height ranges were $1-1.2,1.8-2$, and $2.7-2.9 \mathrm{~m}$, respectively. Two rocks were collected at each height increment; thus 10 per nominal height per day.

In the laboratory, the barnacles were submerged in filtered seawater at the time they would have been covered by the next tide. The following day, $0.5 \mathrm{~h}$ before the tide would otherwise have uncovered them, one individual of size group $S$ from each rock had its shadow response measured $10 \mathrm{~min}$ after initiation of feeding. Since individuals were of necessity tested at 15-min intervals, each barnacle at the time of testing had the same period of time remaining prior to its expected emersion (in the field). In addition, hunger state varied only slightly among individuals: the largest difference in the total time starved (time uncovered in nature plus time in filtered seawater) was $1 \mathrm{~h} 35$ min and the average total time starved was $24 \mathrm{~h}$.

In July 1989, we duplicated this experiment with the exception that cirral beat frequency was measured instead of hiding time. Fewer rocks were required since measurements could be made on more than one barnacle per rock. Total food deprivation time ranged from $24-25 \mathrm{~h}$.

\section{EXPERIMENT IV: RESPONSE TIME VS. TIME TO NEXT EMERSION}

Sixty barnacles of size group $\mathrm{S}$ were collected at $1.8 \mathrm{~m}$ (mid-tide level). Just as they were being covered by the tide, barnacles were collected in groups of 3 (1 for each treatment time interval; see below) at 15-min intervals (to compensate for the time to conduct the tests, as in Exp. III). The barnacles were then submerged in filtered sea water and held overnight in the laboratory; this mimicked the tide regime in the field that night except that water level was held constant and no cues to the tidal cycle were 
provided. Total food deprivation times ranged from $22-26 \mathrm{~h}$ over the course of the experiment (10-12 August 1988), but only $1.5 \mathrm{~h}$ difference existed between treatment groups on a given test day. Finally, 4, 2.5 or $1 \mathrm{~h}$ before its next expected tidal emergence, each barnacle was allowed to feed on Artemia for $10 \mathrm{~min}$ and its shadow response measured. 20 barnacles were tested at each treatment time.

In June 1989, we duplicated this experiment but instead of looking at hiding time, we measured cirral beat frequency as low tide approached. This experiment required fewer rocks and total food deprivation time ranged between 21-24 h.

\section{EXPERIMENT V: RESPONSE TIME VS. STARVATION TIME}

We collected 90 rocks at the $1 \mathrm{~m}$ level as they were being covered by the tide on 18 February 1989. These rocks were held overnight in filtered seawater. The barnacles were then allowed to feed on Artemia nauplii for $1 \mathrm{~h}$. Afterward, the barnacles were rinsed and placed in an aerated tank of filtered seawater. Starting immediately, and at $2 \mathrm{~h}$ intervals thereafter, 2 barnacles on each of 10 rocks had their cirral beat frequency and hiding response measured 10 min after additional Artemia were placed in the tank and feeding had been initiated. Measurements were obtained $0,2,4,6,8,20,22,24$, and $26 \mathrm{~h}$ after the original $(1 \mathrm{~h}$ ) feeding, using different rocks (thus, barnacles) each time. Feeding (and testing) times were staggered slightly so that all individuals at a given test time had identical starvation periods. This experiment was conducted on a day that these barnacles would not have been uncovered by the tide in the field, so tidal effects (cf. Experiment IV) should have been nonexistent.

\section{RESULTS}

\section{EXPERIMENT I: RESPONSE TIME VS. TIME SPENT FEEDING}

A distinct increase in hiding time (ANOVA, $p<0.01$ ) was observed as the amount of time that the barnacles had been feeding increased (Fig. 1). A multiple regression analysis indicated significant effects of feeding time $(p<0.0001)$ and barnacle size (Table $\mathrm{I} ; p<0.01$ ), but not the test group to which the barnacle belonged (i.e., the three groups whose first tests were 5,10 or $15 \mathrm{~min}$ after initiation of feeding).

TABLE I

Overall mean response times of the different size groups in Experiment $I$.

\begin{tabular}{clcccc}
\hline Size group & \multicolumn{2}{c}{ Opercular diameter $(\mathrm{mm})$} & & \multicolumn{2}{c}{ Hiding time $(\mathrm{s})$} \\
\cline { 2 - 3 } & Mean $(N)$ & SD & & Mean $(N)$ & SE \\
\hline S & $2.82(30)$ & 0.43 & $28.7(165)$ & 1.2 \\
M & $4.22(30)$ & 0.36 & & $24.2(167)$ & 1.3 \\
L & $6.38(30)$ & 0.63 & $23.8(155)$ & 1.4 \\
\hline
\end{tabular}




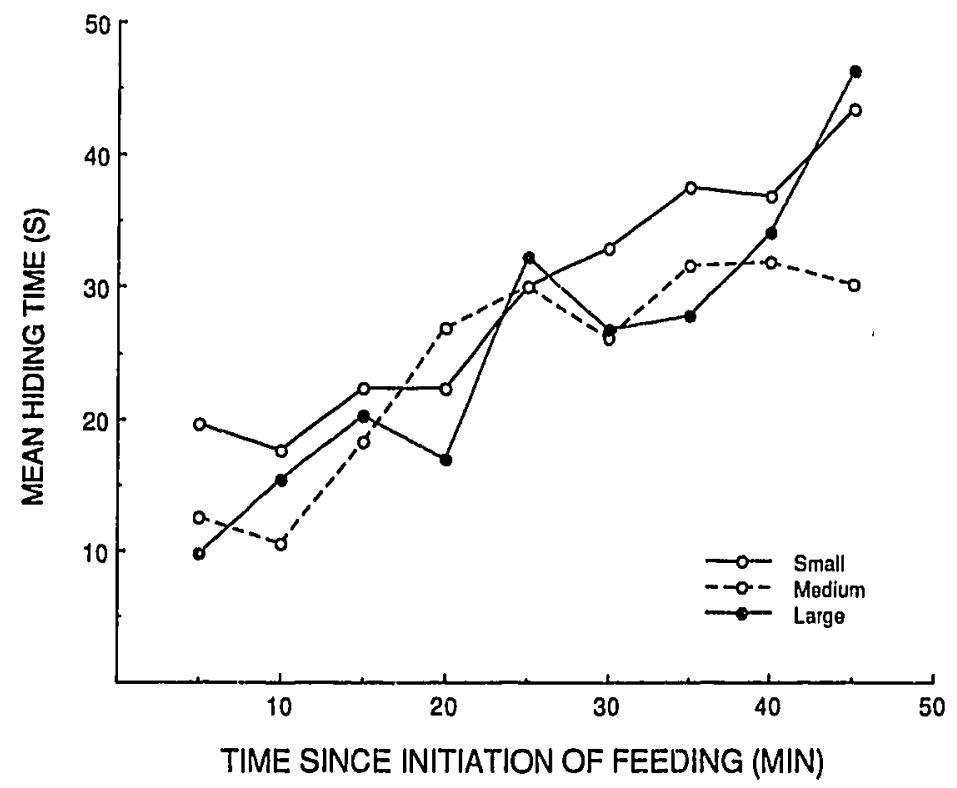

Fig. 1. Mean response times for barnacles of three size classes as a function of the amount of time spent feeding prior to stimulation (Experiment I). The effects of feeding time and barnacle size are both significant. $N=60$ per size class, but only 20 were tested at each time period.

For the sake of simplifying data collection, $60 \mathrm{~s}$ was set as the maximum observation time, and hiding times $>60 \mathrm{~s}$ were set equal to $60 \mathrm{~s}$ in all calculations for this and subsequent experiments. Table IIa gives the total number of response times $>60 \mathrm{~s}$ observed at each time interval. For feeding times of $\leqslant 20 \mathrm{~min}$, only four response times $>60 \mathrm{~s}$ were observed, but for feeding times of $\geqslant 25 \mathrm{~min}, 40$ response times $>60 \mathrm{~s}$ were observed. Setting these response times to $60 \mathrm{~s}$ forced down the mean hiding responses at the later feeding times, underemphasizing to an unknown degree the trend for hiding time to increase with time spent feeding.

As feeding time elapsed, an increasing number of barnacles stopped fast beat (Table IIb) and these barnacles were necessarily omitted from the calculations that produced Fig. 1. Since many more barnacles had stopped fast beat by the later time intervals, sample sizes were smaller at these later times.

\section{EXPERIMENT II: RESPONSE TIME VS. BODY SIZE}

Both hiding time and cirral beat frequency varied significantly with body size (Table III); both decreased significantly with increasing barnacle size, although the response time effect (the opposite of our initial prediction) was the more pronounced. Hiding times $>60 \mathrm{~s}$ were relatively rare $(8 / 80)$. 
TABLE II

(a) Number of hiding times (maximum $=20$ per cell) $>60 \mathrm{~s}$ in relation to time spent feeding prior to stimulation in Experiment l.

\begin{tabular}{lccccccccr}
\hline Size group & \multicolumn{8}{c}{ Time spent fecding (min) } \\
\cline { 2 - 10 } & 5 & 10 & 15 & 20 & 25 & 30 & 35 & 40 & 45 \\
\hline S & 1 & 0 & 0 & 0 & 2 & 0 & 2 & 4 & 7 \\
M & 0 & 1 & 0 & 1 & 0 & 1 & 2 & 4 & 2 \\
L & 0 & 1 & 0 & 0 & 4 & 0 & 3 & 4 & 5 \\
Total & 1 & 2 & 0 & 1 & 6 & 1 & 7 & 12 & 14 \\
\hline
\end{tabular}

(b) Number of barnacles (maximum $=20$ per cell) which had stopped fast beat, in relation to time spent feeding prior to stimulation in Experiment I.

\begin{tabular}{lccccccccr}
\hline Size group & \multicolumn{8}{c}{ Time spent feeding (min) } \\
\cline { 2 - 10 } & 5 & 10 & 15 & 20 & 25 & 30 & 35 & 40 & 45 \\
\hline S & 0 & 0 & 0 & 1 & 1 & 1 & 3 & 2 & 2 \\
M & 0 & 0 & 0 & 3 & 1 & 2 & 2 & 2 & 1 \\
L & 0 & 0 & 0 & 0 & 4 & 4 & 2 & 7 & 7 \\
Total & 0 & 0 & 0 & 4 & 6 & 7 & 7 & 11 & 10 \\
\hline
\end{tabular}

TABLL: III

Hiding time and cirral beat frequency for barnacles of different size (Experiment II). Overall p values determined by ANUVA.

\begin{tabular}{|c|c|c|c|c|c|c|}
\hline \multirow[t]{2}{*}{ Size group } & \multicolumn{2}{|c|}{$\begin{array}{l}\text { Opercular diameter } \\
\qquad(\mathrm{mm})\end{array}$} & \multicolumn{2}{|c|}{ Hiding time (s) } & \multicolumn{2}{|c|}{$\begin{array}{l}\text { Cirral beat } \\
\text { (per } 10 \mathrm{~s} \text { ) }\end{array}$} \\
\hline & $\operatorname{Mean}(N)$ & SD & $\operatorname{Mean}(N)$ & SE & $\operatorname{Mean}(N)$ & SE \\
\hline$T$ & $1.35(30)$ & 0.30 & $37.9(17)$ & 3.9 & $16.1(17)$ & 0.9 \\
\hline $\mathbf{S}$ & $2.82(30)$ & 0.43 & $32.1(19)$ & 3.7 & $14.5(20)$ & 0.5 \\
\hline $\mathbf{M}$ & $4.22(30)$ & 0.36 & $27.7(18)$ & 3.6 & $13.0(18)$ & 0.7 \\
\hline L & $6.38(30)$ & 0.63 & $18.0(18)$ & 3.5 & $11.3(18)$ & 0.5 \\
\hline$p$ & & & 0.0028 & & $<0.0001$ & \\
\hline
\end{tabular}

TABLL: IV

Mean response times and cirral beat frequencies of small barnacles taken from three heights on the shore (Experiment III). There were no significant effects (ANOVAs, $p=0.65$ and $p=0.12$, respectively). NB: Hiding time and cirral beat data were collected in separate experiments.

\begin{tabular}{cccccc}
\hline Height on shore $(\mathrm{m})$ & \multicolumn{2}{c}{ Hiding time $(\mathrm{s})$} & & \multicolumn{2}{c}{ Cirral beat (per 10 s) } \\
\cline { 2 - 3 } & Mean $(N)$ & & Mean $(N)$ & SE \\
\hline 1.0 & $29.7(29)$ & 2.4 & & $12.7(22)$ & 0.7 \\
1.8 & $30.4(24)$ & 2.8 & & $14.2(14)$ & 0.8 \\
2.7 & $26.0(15)$ & 3.2 & & $14.6(21)$ & 0.6 \\
\hline
\end{tabular}




\section{EXPERIMENT III: RESPONSE TIME VS. HEIGHT ON SHORE}

Barnacles from different heights on the beach showed no significant differences in their response times (Table IV), although the highest barnacles did have the shortest average timc. When the 15 actual height categories were used in the analysis, there was still no significant effect. Few response times $>60 \mathrm{~s}$ were observed in this experiment $(5 / 90)$, presumably because testing was conducted only $10 \mathrm{~min}$ after initiation of feeding. The barnacles also showed no significant differences in their rate of cirral beat in relation to shore position although, again, higher barnacles tended to beat more rapidly.

\section{EXPERIMENT IV: RESPONSE TIME VS. TIME TO NEXT EMERSION}

Response times decreased as the time of the next scheduled low tide approached (Table V). The effect is significant (ANOVA, $p<0.001$; data transformed to equalize variance among groups, as $z_{\mathrm{i}}=x_{\mathrm{i}} * 0.1265$ ). Few response times $>60 \mathrm{~s}$ were observed, and excluding them would not alter the pattern. The observed tidal effect cannot be attributed to the slight variation in the hunger state of the animals (see Experiment V). Cirral beat frequency showed no significant change $(p>0.19)$ with time remaining until emersion.

\section{TABLL: V}

Mean response times and cirral beat frequencies of small barnacles at various times prior to their next expected tidal emersion (Experiment IV). Only the hiding time effect was significant (see text). NB: Hiding time and cirral beat data were collected in separate experiments.

\begin{tabular}{cccccr}
\hline Time to next emersion $(\mathrm{h})$ & \multicolumn{2}{c}{ Hiding time (s) } & & \multicolumn{2}{c}{ Cirral beat (per 10 s) } \\
\cline { 2 - 3 } & Mean $(N)$ & $\mathrm{sE}$ & & Mean $(N)$ & $\mathrm{sE}$ \\
\hline 4.0 & $26.0(16)$ & 3.5 & & $15.6(19)$ & 2.2 \\
2.5 & $18.9(18)$ & 2.0 & $17.1(25)$ & 1.3 \\
1.0 & $15.2(17)$ & 3.3 & & $16.4(24)$ & 1.3 \\
\hline
\end{tabular}

\section{EXPERIMENT V: RESPONSE TIME VS. STARVATION TIME}

The average hiding time of the barnacles decreased as their starvation time increased (Fig. 2; note the log scale, suggesting a negative exponential decline). Although the response varied significantly overall (regression of ln hiding times on starvation time; $p=0.0007$ ), there was no significant difference amongst the hiding times in the 20-26-h intervals (ANOVA, $p=0.574$ ). This experiment, therefore, serves as a partial control for earlier experiments in which there were sometimes unavoidable variations in (long) starvation times. The number of hiding times $>60 \mathrm{~s}$, as well as the number of individuals not fast-beating, tended to decrease as starvation time increased (Table VI); whereas there were 11 hiding times $>60 \mathrm{~s}$ and 11 animals not fast-beating in the first five time 
TABLE VI

Number of hiding times $>60 \mathrm{~s}$, and number of barnacles that did not fast beat, in relation to starvation time (Experiment V). Maximum $=20$ per cell for each measure.

\begin{tabular}{llllllllllr}
\hline \multicolumn{1}{c}{ Measure } & \multicolumn{10}{c}{ Time starved (h) } \\
\cline { 2 - 11 } & 0 & 2 & 4 & 6 & 8 & 20 & 22 & 24 & 26 \\
\hline Hiding times $>60 \mathrm{~s}$ & 2 & 1 & 2 & 3 & 3 & 0 & 0 & 1 & 1 \\
Not fast beating & 4 & 0 & 4 & 2 & 1 & 1 & 0 & 0 & 2 \\
\hline
\end{tabular}

intervals, there were only two hiding times $>60 \mathrm{~s}$ and three animals not fast-beating in the last four intervals. Finally, no significant change was observed in cirral beat frequency as starvation time increased (ANOVA, $p=0.38$ ), and no trend was apparent.

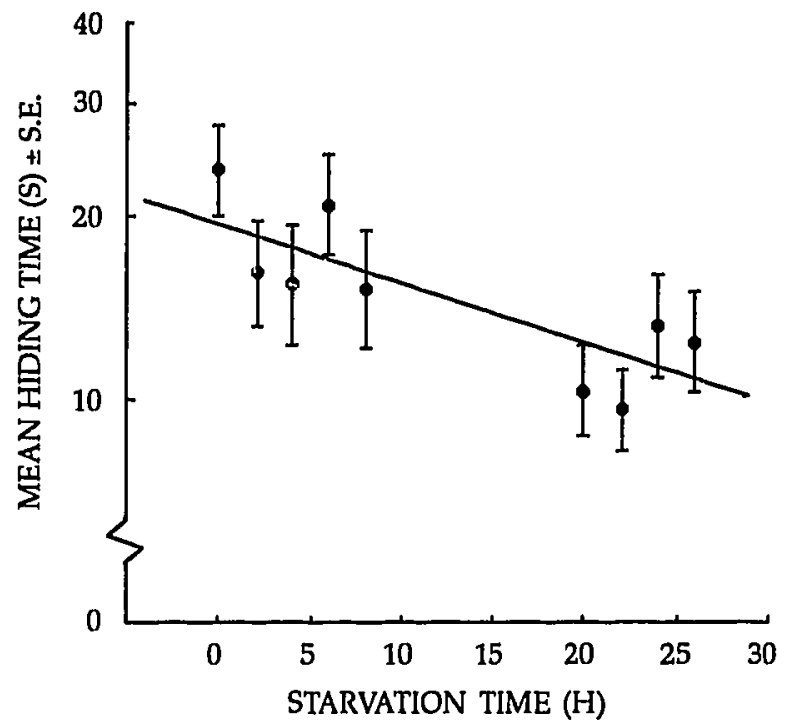

Fig. 2. Mean hiding times of barnacles ( $\pm \mathrm{ISL}$ ) as a function of the length of time starved prior to testing (Experiment $\mathrm{V}$; note $\log$ scale). The decrease is significant overall but not between $20-26 \mathrm{~h}$ (ANOVA on In-transformed data, $p=0.574$ ). The maximum $n$ at each starvation time was 20 , but was usually smaller than this since individuals who were not performing fast beat (Table VI) were excluded. The line is the regression best describing the data: $\ln y=2.96-0.022 x$.

\section{Discussion}

The shadow response times of the barnacles increased with the amount of time they had been feeding at the time of stimulation. This tendency can be explained in terms of changes in the relative values of feeding and hiding. When the barnacles have just begun to feed after a period of starvation each additional unit of feeding time is more 
valuable to them than it is after they have been feeding for some time and their energy deficit has been reduced (McNamara \& Houston, 1986). It follows that the lost-opportunity cost of hiding is higher when the barnacles have just begun to feed. Meanwhile, the risk of predation mortality associated with a shadow presumably remains constant. Thus, the barnacles are willing to invest less time in hiding when they have just begun to feed but invest increasing amounts of time in hiding the longer they have been feeding. The observation that barnacles of different sizes exhibit the same pattern of change in hiding times suggests that the relative value of feeding to risk changes in the same way for all size classes (this implies the same rate of satiation).

Despite this consistent temporal pattern of hiding behavior, the smallest barnacles exhibited the longest hiding times. The apparently lower cost of lost feeding time to small barnacles may be explained in part by their relatively high beat frequency, making it easier for them to recoup the cost of hiding. Small individuals also beat faster than large ones in the ecologically similar B. balanoides (Newell \& Northeroft, 1965) although this may just compensate for the smaller cirral net (Crisp \& MacLean, 1990). The fact that eggs were observed only in the large $B$. glandula may also be a factor; feeding rate decreases during incubation in $B$. balanoides (Stubbings, 1975). It is also conceivable that small barnacles may be at greater predation risk, thus increasing the benefit of hiding. Palmer et al. (1982) found no effect of size on shadow response time in $B$. glandula. We cannot explain this difference, but note that their mean response times are in all cases considerably less than those reported here.

As noted earlier, the $60 \mathrm{~s}$ ceiling on response time leads to the underestimation of average response times. Thus, the tendency for response time to increase with feeding time is actually stronger than revealed by our data. Likewise, the omission of barnacles not performing fast beat dampened the observed effect of feeding time on response time; barnacles that had stopped fast beat had presumably become satiated, and might have displayed very long response times had they continued to be available for testing.

The response times of barnacles from different heights on the shore did not differ, although predicted to do so both by ourselves and by Palmer et al. (1982). Although B. balanoides individuals from higher on the shore feed on Artemia nauplii at a higher rate than do individuals from lower on the shore (Ritz \& Crisp, 1970), the present study found no such trend, at least as measured by cirral beat frequency. Thus, $B$. glandula do not use cirral beat frequency to compensate for the shorter feeding times available higher on the shore, and their failure to exhibit shorter hiding times in such circumstances cannot presently be explained.

The decreasing hiding times of the barnacles as low tide approaches can be explained in terms of changes either in future feeding opportunity or risk. As the amount of remaining feeding time decreases with the ebbing tide, the relative value of each additional unit of feeding time may increase since growth and reproductive output (thus fitness) may be maximized if animals can enter low tide periods with full guts and carry out digestion at these times. Thus, as low tide approaches, hungry barnacles (as in these experiments) might be expected to be relatively more concerned with feeding than with 
security. Whether this is actually the case will depend upon a variety of environmental factors, such as predation rate and food availability, and upon the relationship between food intake and fitness. These could be incorporated into a dynamic programming model (Mangel \& Clark, 1988) to make predictions about barnacle behaviour in various circumstances.

There are other possible explanations for the change in barnacle behaviour as the tide drops. First, increasing turbulence in progressively shallower water may resuspend food particles, improving fecding conditions and increasing the lost opportunity cost of hiding. Secondly, it is possible that as the water becomes increasingly shallow, predators move offshore and predation risk diminishes. Of course, these effects (all of which imply an economic logic underlying the barnacles' behavior) may operate simultaneously. The results obtained in this experiment also suggest that these barnacles possess endogenous tidal rhythms, contrary to earlier reports (Southward \& Crisp, 1965).

The decrease in hiding time with increased starvation is readily explained by the increasing value of feeding opportunity relative to risk as the animal becomes progressively more hungry. The decrease in the number of response times $>60 \mathrm{~s}$, as well as the increase in the proportion of barnacles fast-beating, further support the idea of an increase in the relative value of feeding as starvation proceeds. The fact that bchavior stabilizes after 8-20 h deprivation may be a consequence of the gut becoming maximally empty sometime in that period (cf. Svirenko, 1961), such that perceived hunger no longer changes.

Cirral beat frequency is remarkably constant in B. glandula, varying only with body size. It does not appear that individual barnacles vary their feeding rate to compensate either for low overall food availability (i.e., high positions on the shore), hunger level, or worsening conditions (i.e., a falling tide). In contrast, their hiding times in response to presumed predatory threats vary in a way which suggests that barnacles make adaptive trade-offs between the benefits and costs of their actions in some circumstances.

\section{ACKNOWLEDGEMENTS}

We sincerely appreciate the competent technical assistance of $A$. Fraser. We also thank R. Cartar, D. Gillis and D. Soluk for statistical advice, S. Forbes and E. Charnov for helpful discussion, and R. Ydenberg for comments on the manuscript. Financial support was provided by NSERC Canada Grant A6869 to L. M. Dill and by a Challenge 1988 summer employment grant (towards J.F. Gillett's salary).

\section{REFERENCES}

Crisp, D.J. \& F.J. MacLean, 1990. The relation between the dimensions of the cirral net, the beat frequency and the size and age of the animal in Balamus balanoides and Elminius modestus. J. Mar. Biol. Assoc. U.K., Vol. 70, pp. 505-514. 
Crisp, D.J. \& A.J. Southward, 1961. Different types of cirral activity of barnacles. Phil. Trans. R. Soc. London B., Vol. 243, pp. 271-.307.

Dill, L.M., 1987. Animal decision making and its ecological consequences: the future of aquatic ecology and behavior. Can. J. Zool., Vol. 65, pp. 803-811.

Hurley, A.C., 1973. Fecundity of the acorn barnacle Balamus pacificus Pilsbry: a fugitive species. Limmol. Oceculogr., Vol. 18, pp. 386-393.

Lima, S.L. \& L.M. Dill, 1990. Behavioral decisions made under the risk of predation: a review and prospectus. Can. J. Zool., Vol. 68, pp. 619-640.

Mangel, M. \& C.W. Clark, 1988. Dymamic modeling in behavioral ecology. Princeton University Press, Princeton, New Jersey, $308 \mathrm{pp}$.

McNamara, J. M. \& A. I. Houston, 1986. The common currency for behavioral decisions. Am. Nat., Vol. 127, pp. 358-378.

Newell, R.C. \& H.R. Northcroft, 1965. The relationship between cirral activity and oxygen uptake in Balamus balanoides. J. Mar. Biol. Assoc. U.K., Vol. 45, pp. 387-403.

Palmer, A.R., J.S. Szymanska \& L. Thomas, 1982. Prolonged withdrawal: a possible predator evasion behavior in Balamus glandula (Crustacea : Cirripedia). Mar. Biol., Vol. 67, pp. 51-55.

Pearse, V., J. Pearse, M. Buchsbaum \& R. Buchsbaum, 1987. Living invertebrates. Blackwell Scientific Publications, Palo Alto, California, $848 \mathrm{pp}$.

Pilsbry, H.A., 1916. The sessile barnacles (Cirripedia) contained in the collections of the U.S. National Musetm; including a monograph of the American species. Government Printing Office, Washington, DC, $366 \mathrm{pp}$.

Ritz, D.A. \& D.J. Crisp, 1970. Scasonal changes in feeding rate in Balanus balanoides. J. Mar. Biol. Assoc. U.K., Vol. 50, pp. 223-240.

Southward, A.J., 1955. On the behavior of barnacles. II. The influence of habitat and tide level on cirral activity. J. Mar. Biol. Assoc. U.K., Vol. 34, pp. 423-433.

Southward, A.J. \& D.J. Crisp, 1965. Activity rhythms of barnacles in relation to respiration and feeding. J. Mar. Biol. Assoc. U.K., Vol. 45, pp. 161-185.

Stubbings, H.G., 1975. Balanus balamoides. Liverpool University Press, Liverpool, 175 pp.

Svirenko, E.G., 1961. The problem of the nutrition of Black Sea barnacles. Referat. Zhur. Biol. 12D41. [As seen in Biol. Abstr., Vol. 38, No. 7913.]

Wethey, D.S., 1983. Intrapopulation variation in growth of sessile organisms: natural populations of the intertidal barnacle, Bulanus balanoides. Oikos, Vol. 40, pp. 14-23.

Wu, R. S. S. \& C. D. Levings, 1978. An energy budget for individual barnacles (Balanus glandula). Mar. Biol., Vol. 45, pp. 225-235.

Wu, R.S. S. \& C. D. Levings, 1979. Energy flow and population dynamics of the barnacle Balanus glandula. Mar. Biol., Vol. 54, pp. 83-89.

Ydenberg, R.C. \& L.M. Dill, 1986. The economics of fleeing from predators. Adv. Sudy Behav., Vol. 16, pp. 229-249. 